\title{
Rotavirus gastroenteritis among hospitalized children under 5 years of age in the Eastern Mediterranean Region: a review
}

Mohamed Nasr Fathi Shaheen ${ }^{1}$

${ }^{1}$ Department of Water Pollution Research, Environmental Research Division, National Research Centre, Cairo, Egypt. (Correspondence to: Mohamed Nasr Fathi Shaheen: m_nrc2007@yahoo.com).

\begin{abstract}
Background: Rotavirus(RV) is one of the primary causes globally of acute diarrhoea in children below 5 years of age.

Aims: This literature research aims to evaluate the rotavirus diarrhoea among hospitalized children $<5$ years of age in the Eastern Mediterranean Region from 2010 to 2016. Data from each country were extracted and compared.

Methods: An extensive literature search was carried out using the following databases: PubMed, Google Scholar and Science Direct, with the keyword "Rotavirus". The search was limited to articles published from January 2010 to December 2016.

Results: The search identified 28 studies. Rotavirus gastroenteritis (RVGE) identification in studies countries ranged from from $19 \%-78.2 \%$ of all tested diarrhoeal specimens, primarily in children $\leq 1$ year of age. RV occurred throughout the year, with peak incidence during autumn and winter seasons. G1P[8] was the predominant circulating genotype combination followed by G9P[8] and G2P[4]. Out of 28 studies, only one examined the economic burden which ranged from US\$ 245 to $\$ 345$ per hospitalized child due to RV diarrhoea. Moreover, three days were the minimum duration of hospitalization. No available data on the mortality rates due to RVGE among the selected studies.

Conclusions: This research documents that RV is one of the most significant pathogens that cause morbidity and mortality in the paediatric population in Eastern Mediterranean Region countries. The data from this literature research may help public healthcare workers in decreasing mortality and morbidity resulting from RVGE in the region.

Keywords: rotavirus, gastroenteritis, diarrhoea, mortality, vaccine, children

Citation: Shaheen MNF. Rotavirus gastroenteritis among hospitalized children under 5 years of age in the Eastern Mediterranean Region: a review. East Mediterr Health J. 2019;25(6):422-430 https://doi.org/10.26719/emhj.18.054

Received: 01/05/17; accepted: 25/10/17

Copyright (c) World Health Organization (WHO) 2019. Some rights reserved. This work is available under the CC BY-NC-SA 3.0 IGO license (https:// creativecommons.org/licenses/by-nc-sa/3.o/igo)
\end{abstract}

\section{Introduction}

Human rotavirus group A (human RV-A) is one of the global environmental risks that causes acute diarrhoea in children aged under five years, and accounts for 527000 deaths per year, of which $82 \%$ occur among the paediatric population in the poorest countries $(1,2)$. Morbidity and death caused by rotavirus occur mainly in low- and middle-income countries, particularly those with poor health care systems (3).

Rotavirus is a non-enveloped virus within the family of Reoviridae. The genome of this virus consist of 11 double-stranded RNA segments and based on the 2 surface capsid segments $\mathrm{VP}_{4}$ and $\mathrm{VP}_{7}$; RV is classified into $P$ and $G$ serotypes, respectively (4). To date, $27-G$ and 37-P genotypes have been described in humans (5). Several epidemiological studies reported that the $\mathrm{G}_{1} \mathrm{P}[8], \mathrm{G}_{2} \mathrm{P}[4]$, $\mathrm{G}_{3} \mathrm{P}[8], \mathrm{G}_{4} \mathrm{P}[8], \mathrm{G}_{9} \mathrm{P}[8]$, and $\mathrm{G}_{12} \mathrm{P}[8]$ combinations are the major causes of rotavirus gastroenteritis in humans $(6,7)$. Currently, two live-attenuated oral rotavirus vaccines (Rotarix and RotaTeq) were licensed for infants < 6 months old. Rotarix (GlaxoSmithKline, Rixensart, Belgium) contains human $\mathrm{G} 1 \mathrm{P}[8]$ serotype while RotaTeq (Vaccines, Whitehouse Station, NJ, USA) contains a mixture of five human serotypes $\mathrm{G}_{1}-\mathrm{G}_{4}$ and $\mathrm{P}[8]$.
Both vaccines appear to protect against diarrhoeal diseases caused by RV infection (8). This study was designed to update the knowledge of circulating human RV-A G and P genotypes in the Eastern Mediterranean Region, through conducting a comprehensive literature review that assessed the distribution of rotavirus among children younger than 5 years of age with diarrhoea. The data would be beneficial before, during, and after the rotavirus vaccine introduction in populations.

\section{Methods}

In order to identify the impact of RV gastroenteritis on the paediatric population under five years of age in the Middle East (Algeria, Bahrain, Egypt, Islamic Republic of Iran, Iraq, Jordan, Kuwait, Libya, Morocco, Oman, Qatar, Saudi Arabia, Syrian Arab Republic, Tunisia, United Arab Emirates, Yemen) as well as Turkey for its regional proximity, an extensive literature search was carried out using the following databases: PubMed, Google Scholar and Science Direct, with the keyword "Rotavirus". The search was limited to articles published in the last seven years (January 2010 to December 2016) that met the following criteria: 1 ) hospitalized children $\leq 5$ years of age with acute diarrhoea; 2 ) period of sample collection $\geq 12$ 
months; 3 ) number of tested samples for rotavirus $\geq 100$; and 4) detection of RV was performed using a sensitive methods such as an enzyme immunoassay (EIA), latex agglutination (LAT), polyacrylamide gel electrophoresis (PAGE), or reverse-transcriptase polymerase chain reaction (PCR).

The proportion of RV infection was extracted from all selected studies and calculated by study and country. In case a single country had several published studies, a pooled average of the proportion of $\mathrm{RV}$ diarrhoea among cases of acute diarrhoea was calculated and reported. Also, the percentage of rotaviral genotype combinations among children suffering from RV gastroenteritis was calculated by study. Overall, the mean proportion of RV infection and genotype combinations among hospitalized children under 5 years of age in the MENA region was calculated from a combination of all extracted data. Moreover, age and gender distributions, seasonal variation, genotypes of $\mathrm{RV}$, intravenous rehydration, duration of hospital stay, and medical costs were extracted from the selected studies and compared. Disease severity was measured by using 20-point Vesikari scores, based on the duration of diarrhoea, vomiting, intensity of diarrhoea, fever, and dehydration. A severe disease occurs when a Vesikari score is more than $11(9)$.

\section{Results}

\section{Studies selected for review}

We reviewed 145 articles/abstracts to select a total of 28 that met the inclusion criteria of the current review (Figure 1). The selected studies covered Bahrain (10), Egypt (11,12), Islamic Republic of Iran (13-21), Iraq (22,23), Jordan (24,25), Libya (26), Morocco (27-29), Saudi Arabia (30-32), Tunisia (33), Turkey (34,35), United Arab Emirates (UAE) (36), and Yemen (37). All studies from Algeria, Jordan, Leb- anon, Oman, Palestine, and Qatar were excluded because these did not meet our inclusion criteria whereas no studies were available from Kuwait and the Syrian Arab Republic. The included studies in the current review contained the following topics: proportion of RV gastroenteritis $(n=28)$, seasonal variation $(n=21)$, age distribution $(n=23)$, gender distribution $(n=19)$, genotype distribution ( $n=15)$, and disease severity ( $n=13$ articles).

\section{Proportion of RV gastroenteritis among hospitalized children}

Twenty-eight studies from 12 countries contained data on the proportion of RV gastroenteritis among hospitalized children under five years of age in the Middle East and North Africa region. These studies contained 17233 diarrhoeal samples and tested for RV gastroenteritis. Of these, 7366 (42.7\%) children had RV infection. By country, the mean percentage of cases caused by rotavirus infection ranged from $316(22.5 \%)$ to 1885 (63\%). Egypt, Tunisia, and Islamic Republic of Iran reported the lowest proportion with $316(22.5 \%), 65(23.3 \%)$, and $537(27.4 \%)$, respectively. The highest proportion was observed in Turkey 1885 (63\%), UAE 381 (50.3\%), and Saudi Arabia 1226 (48.7\%). The other countries reported a percentage of between 93 (35.8\%) and 358 (45.2\%) (Figure 2).

\section{Variation in the proportion of $\mathrm{RV}$ gastroenteritis over time}

Among hospitalized children with acute diarrhoea, the proportion of RV gastroenteritis have fallen in Morocco from $741(40 \%)$ to $89(26.6 \%)$ between 2006 and 2011 $(27,29)$, and in Saudi Arabia from $660(65.5 \%)$ to 171 (31.6\%) between 2008 and $2012(30,32)$. The proportion of RV gastroenteritis appears to have increased over time in Islamic Republic of Iran from 131 (19\%) to $10(25 \%)$ between

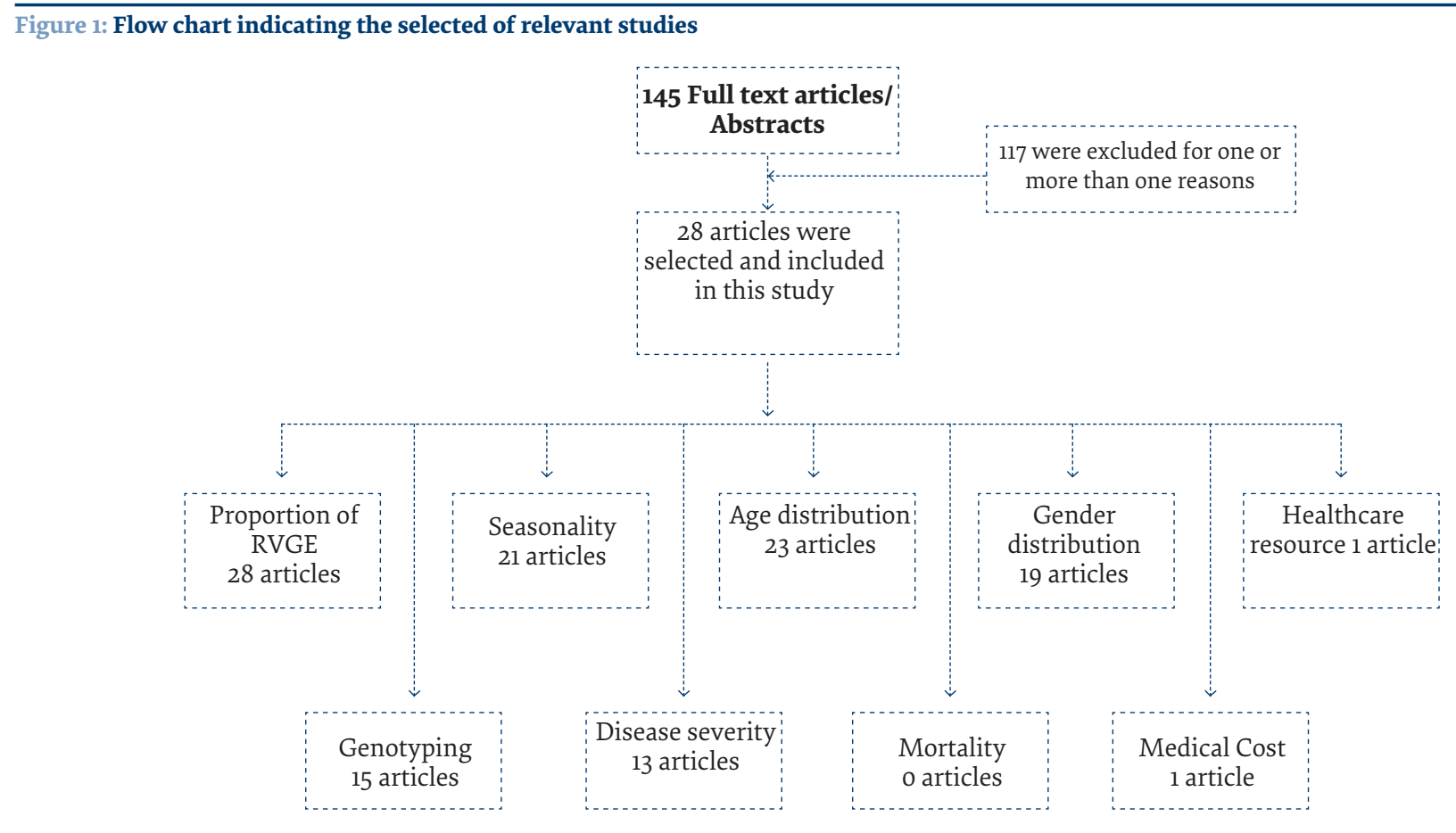




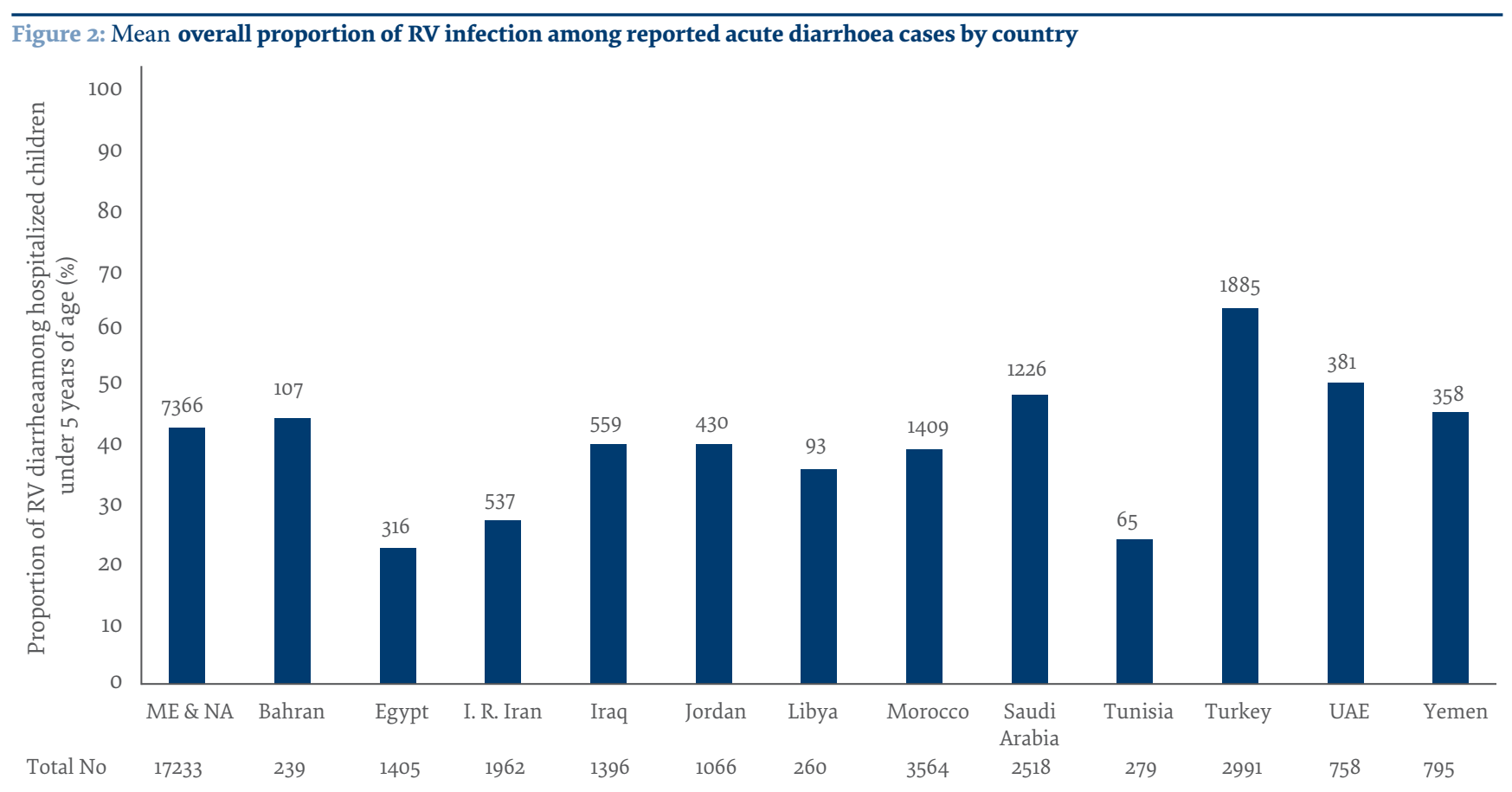

2004 to 2014 (14,21), and in Turkey from $241(28 \%)$ to 1644 (78.2\%) between 2006 and 2014 (34,35) (Table 1).

\section{Seasonal distribution of RV gastroenteritis}

Twenty-one studies from 12 countries including Bahrain (10), Egypt (12), Islamic Republic of Iran (13,15-19,21), Iraq (22), Jordan (25), Libya (26), Morocco (26-28), Saudi Arabia (31,32), Tunisia (33), Turkey (34), UAE (36) and Yemen (37), reported seasonality distribution (Table 2). Most RV infection was found in winter and autumn. In contrast, three studies from Islamic Republic of Iran, Iraq and Yemen concluded that the peak incidence of rotaviral infection was found in summer $(16,22,37)$ (Table 2).

\section{Gender distribution of children with RV gastroenteritis}

Nineteen studies from nine countries including Bahrain (10), Islamic Republic of Iran (13,15-21), Iraq (22), Jordan (25), Morocco (29), Saudi Arabia (30-32), Tunisia (33), Turkey (34,35), and Yemen (37) contained data on gender distribution. All studies found that the frequency of diarrhoea for Rotavirus was higher in males (Table 2).

\section{Age distribution of children with RV gastroenteritis}

Data on age distribution (Table 2) were available in 23 studies from the following countries: Bahrain (10), Egypt (12), Islamic Republic of Iran $(13,15-18,21)$, Iraq $(22,23)$, Jordan (24,25), Libya (26), Morocco (27-29), Saudi Arabia (30-32), Tunisia (33), Turkey (34), UAE (36), and Yemen (37). Children aged 6-12 months had the highest rate of positive samples for RV (15,18,22-24,26-29,31). A limited number of studies stated that the peak distribution of RV infections was observed in age group ranged from 6-23 months $(10,17,25,33)$, whereas the majority of RV infection occurred in children aged $<12$ months in three studies from Egypt and Saudi Arabia $(12,30,32)$. A number of studies reported that most RV infections occurred in the age group from 12-24 months $(13,16,21,34,36)$. Only one study reported that most RV gastroenteritis occurred among children aged 1-6 months (37).

\section{Distribution of human RV G and P combination in children with gastroenteritis}

Out of 28 studies, 15 studies from 11 countries - Bahrain (10), Egypt (11), Islamic Republic of Iran (14), Iraq (23), Jordan (24,25), Morocco (28,29), Saudi Arabia (31,32), Tunisia (33), Turkey (34,35), UAE (36) and Yemen (37) - studied the human RV G-P combinations in 4070 hospitalized children with RV gastroenteritis. Overall, G1P[8] combination represented the predominant genotype followed by G9P [8] and $\mathrm{G}_{2} \mathrm{P}[4]$ in the MENA region, in 1535 (37.7\%), $916(22.5 \%)$, and $331(8.1 \%)$ of all RV positive samples, respectively. G1P [8] combination was detected in 14 studies from 10 countries $(10,11,14,23-25,28,29,31,32,34-37)$. G1P[8] was the most prevalent in 11 of those studies, accounting for between $6(6 \%)$ and 171 (69\%) of genotyped RV gastroenteritis samples in those countries. G9P[8] was present in seven countries (Bahrain, Egypt, Jordan, Morocco, Saudi Arabia, Turkey and UAE) where it was the most prevalent genotype in Morocco during 2006-2009 (28), and Turkey during 2006-2014 (34,35). In addition, G2P[4] was detected in all countries except Islamic Republic of Iran, Tunisia, and UAE. G2P[4] was the highest circulating genotype from November 2006 to February 2008 in Yemen (37) (Figure 3).

Uncommon RV genotype combinations in the MENA region (Figure 3 and Figure 4) were detected in multiple countries and accounted for $5 \%$ or less of the 
Figure 3: Distribution of G-P combinations of RV in The Middle East and North Afirca . ${ }^{*}$ Other includes rare G-P combinations, mixed genotype combinations, partially typable, and non-typable specimens

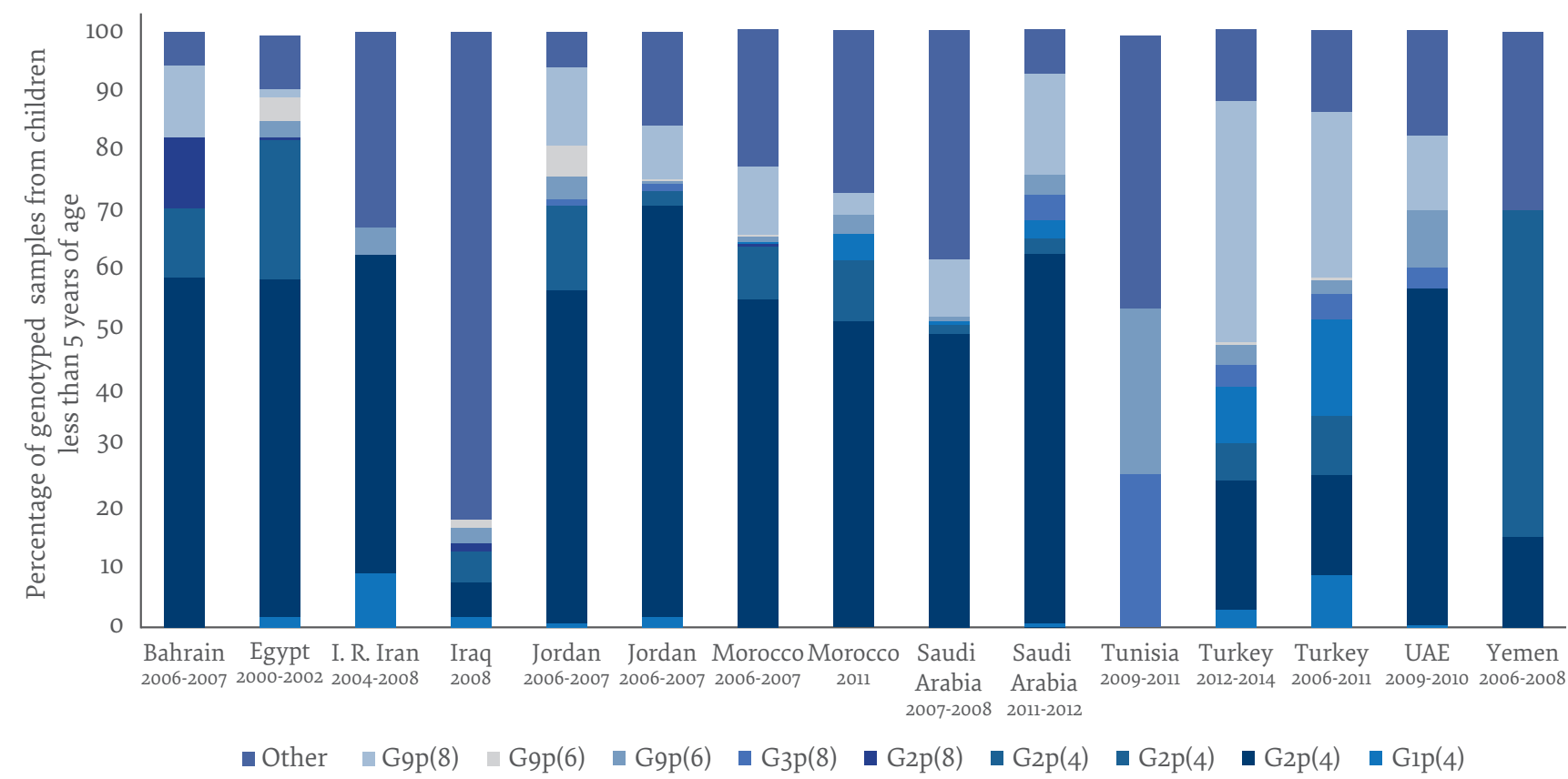

total genotypes during 2010-2016, including G1P[4] in Egypt (11), Islamic Republic of Iran (12), Iraq (23), Jordan $(24,25)$, Morocco (28), Saudi Arabia (32), Turkey $(34,35)$, UAE (36); G1P[6] in Egypt (11), Iraq (23), Morocco $(28,29)$, UAE (36); G2P[8] in Bahrain (10), Egypt (11), Iraq (23), Morocco $(28,29)$, Saudi Arabia (31,32), Turkey $(34,35) ; \mathrm{G} 3 \mathrm{P}[8]$ in Jordan (24,25), Morocco (28), Saudi Arabia (32), Tunisia (33), Turkey (34,35), UAE (36); G4P[8] in 13 of 15 studies (11,14,23-25,28,29,31-36); and G9P[6] in Egypt (11), Iraq (23), Jordan (24,25), Morocco (28) and Turkey $(34,35)$.

Rare RV genotype combinations such as $\mathrm{GiP}[9]$, $\mathrm{G}_{2} \mathrm{P}[6], \mathrm{G}_{3} \mathrm{P}[4], \mathrm{G}_{3} \mathrm{P}[6], \mathrm{G}_{4} \mathrm{P}[4], \mathrm{G}_{4} \mathrm{P}[6], \mathrm{G}_{4} \mathrm{P}[9], \mathrm{G}_{5} \mathrm{P}[4]$, G5P[8], G8P[4], G8P[6], G8P[8], G9P[4], G9P[9], G9P[10], G10P[8], G12P[6], G12P[8], G12P[11], were detected in three countries or less as follows: G1P[9] in Turkey (34); G2P[6] in Iraq (23), Morocco (28) and Turkey (35); G3P [4] in Egypt (11), Morocco (28) and Turkey (34); G3P [6] in Iraq (23) and Morocco (28); G4P [4] in Jordan (24) and Turkey (34); G4P[6] in Iraq (23); G4P[9] in Turkey (34); G5P [4] in UAE (36); G5P [4] in UAE (36); G5P[8] in UAE (36); G8P[4] in Turkey (34); G8P[6] in Iraq (23); G8P[8] in Turkey (34) and UAE (36); G9P[4] in Jordan (24), Turkey (34), and UAE (36); G9P[9], G9P[10], and G10P[8] in Turkey (34); G12P[6] and $\mathrm{G}_{12} \mathrm{P}$ [8] in Iraq (23), Saudi Arabia (31), Turkey (34); and G12P[11] in Turkey (34). The results are summarized in Table 3 .

Mixed genotypes, partially or non-typeable RV genotypes were pooled in the "Other" category in Figure 4. Mixed RV genotypes were identified in nine studies / eight countries $(11,14,23,24,28,29,31,34,36)$, with a mean proportion of $191(4.7 \%)$ of the total rotavirus positive samples during 2010-2016. Non-typeable and partially typed RV genotypes were detected in seven studies / seven countries $(10,11,25,29,31,35,36)$ and 12 studies / 10 countries (11,14,23-25,28,31,33,34-37), respectively. They accounted for $161(4 \%)$ to $68(1.7 \%)$ of all genotypes in the MENA region during 2010-2016, respectively.

\section{Clinical features and disease severity}

Thirteen studies from the studied region provided data on clinical manifestations caused by RV gastroenteritis in the following countries: Bahrain (10), Egypt (12), Islamic Republic of Iran (15,16), Iraq (22), Libya (26), Morocco $(27,29)$, Saudi Arabia $(31,32)$, Tunisia (33), UAE (36) and Yemen (37). In most cases, RV-positive children suffered from vomiting $(10,12,15,16,22,26,27,29,31-33,36,37)$, dehydration $(10,26,27,29,31-33,36,37)$, and fever $(12,15,16,22,31,33,36,37)$. Convulsion was reported in two studies from Islamic Republic of Iran 3 (6.25\%) (15) and Iraq 7 (4\%) (22). Disease severity was measured by the Vesikari scale in two studies from Morocco with a mean score of 86.4 (11.66\%, $P=$ $0.13)$ vs. $126.6(11.51 \%)$ of non-RV gastroenteritis (27) and 11.5 (14.74\%, $P<0.0001)$ vs. 23.6 (12.3\%) of non-RV gastroenteritis (29), which increased to $16.5(17.8 \%, P=0.001)$ vs. $26.2(15.7 \%)$ of RV gastroenteritis and $102(25 \%, P=0.0005)$ vs. 133 (23.4\%) of non-RV gastroenteritis in Libya (26) and Saudi Arabia (31) during hospitalization, respectively. The higher severity score was identified in a study from UAE with 161 (42.3\%, P = 0.0031 vs. 117 (31\%) of non-RV gastroenteritis (36). No deaths were reported in all included studies.

\section{Intravenous rehydration}

Seven studies from Bahrain (10), Libya (26), Morocco (27), Saudi Arabia (31), Tunisia (33), UAE (36) and Yemen (37) reported that 106 (99.6\%), 93 (100\%), $627(84.5 \%), 387$ (98\%), $28(77.7 \%), 337(99 \%)$ and $421(53.0 \%)$ of all hospitalized 


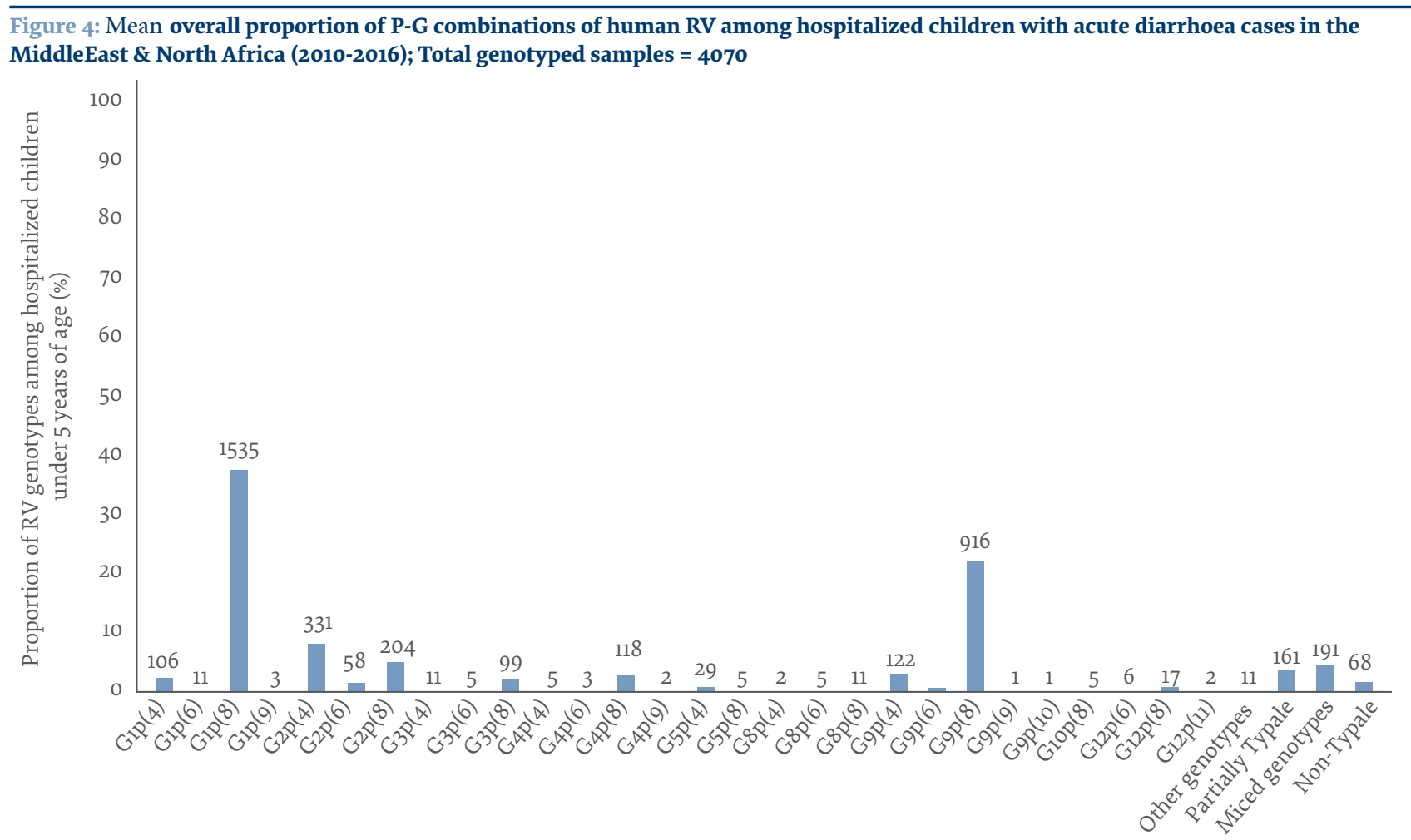

children with RV diarrhoea received Intravenous rehydration therapy, respectively.

\section{Duration of hospital stay}

The mean $( \pm$ SD) duration of hospitalized children with RV diarrhoea was $4.1( \pm 2.41), 3$, and $4.0( \pm 1.8)$ days in three studies from Bahrain (10), Morocco (27), and Saudi Arabia (31), respectively. Health care utilization and economic burden resulted from RV gastroenteritis. One study from Tunisia contained data on healthcare resource use with a mean cost ranging from US\$245 to \$345 per hospitalized child with RV diarrhoea (33).

\section{Discussion}

Rotavirus is a major cause of gastroenteritis in humans in both low- and middle-income countries as well as high-income countries. A continuous survey to identify the most common RV strains responsible for severe gastroenteritis is an important tool for vaccine selection and production to prevent rotavirus infection in the EasternMediterranen Region. Based on collected data from 28 studies in studied countries, our analysis revealed that $\mathrm{RV}$ is a major cause of diarrhoeal disease in children under 5 years of age in all included countries.

The detection rates of RV were different between these countries and can be explained by the differing conditions of these studies, such as geographical area, number of collected samples, RV antigen concentration in the collected samples, season of sample collection, and the sampling methods. In the studied region (2010-2016), RV infections were responsible for $42.7 \%$ of all diarrhoeal cases in children $<5$ years of age. This finding is close to studies published by Centers for Disease Control and Prevention (CDC), where $40 \%$ was the median RV detection rate in the Eastern Mediterranean Region during 2001-2008 (38). Forster et al. (39) reported that RV gastroenteritis accounted for $43.4 \%$ of diarrhoeal cases in European children $<5$ years of age from February 2005 to August 2006.

According to our survey, the majority of $\mathrm{RV}$ gastroenteritis was detected in children aged 6-23 months, which is in agreement with previous reports on the epidemiological profile of RV infection (40-42). This may be explained by the protection that was given by maternal antibodies in the first six months of the child's life rather than the immunity acquired after two years of age due to repeated exposure (43). Based on this explanation, preventive strategies should occur during infancy. Moreover, RV infection was detected in all seasons but primarily during cooler months, as reported by McNulty (44) who found RV tends to be more common in winter than summer. It has been suggested that the low humidity of these seasons and combination of rainfall with drying soils might lead to an increase in the aerial transportation of dried and faecal contaminated materials $(45,46)$. Moreover, the prevalence of acute gastroenteritis due to RV infection was higher in males than in females. This finding is similar to other studies conducted in Lebanon, Japan, and Nepal (41,47,48).

In this survey, $\mathrm{G}_{1} \mathrm{P}[8]$ genotype combination was the most common in MENA countries during 2010-2016. $\mathrm{G} 9 \mathrm{P}[8]$ was second in frequency; however, it was the predominant genotype in Turkey during 2012-2014 (34). In spite of the presence of $\mathrm{G}_{2} \mathrm{P}[4]$ at low levels (median 
$8.1 \%$ of all genotyped specimens), it was detected in all studies $(10,11,23-25,28,29,31,32,34,35,37)$ except three studies from Islamic Republic of Iran (14), Tunisia (33), and UAE (36). In comparison with other studies, G1P[8] and G2P [4] genotype combinations were the most common in MENA, central and Eastern European countries during 1999-2009 (49) based on studies from 2005/2006 and 2007/2008 (50). In spite of G4P[8] genotype detected at low levels (median $2.9 \%$ of all genotyped specimens), it was detected in all studies (11,14,23-25,28,29,31-36), except two studies from Bahrain (10) and Yemen (37).

In contrast, G2P[6] genotype combination was detected only in three studies $(23,28,35)$; however, it was the predominant genotype during 2008 in Iraq (23). Moreover, other genotype combinations such as $\mathrm{G}_{1} \mathrm{P}[4], \mathrm{G}_{2} \mathrm{P}[8], \mathrm{G}_{3} \mathrm{P}[8]$ and $\mathrm{G}_{9} \mathrm{P}[4]$ were detected in different countries but at a level $\leq 5 \%$ of all genotypes. Iturriza-Gomara et al. (51) reported that these genotypes belong to the most characterized RV strains that can cause diarrhoeal diseases in humans. Collectively, these findings imply that the current Rotarix vaccine, containing $\mathrm{G}_{1} \mathrm{P}[8]$, is still the most predominant circulating strain in the studied countries.

In our analysis we find differences in the percentage of non-typeable (median 1.7; range, $0.4-10.8 \%$ of all genotypes samples) and partially types (median 4; range, $0.4-29.7 \%$ of all genotype samples), which may be attributed to occurrence of novel strains that were not determined in these studies or occurrence of differences and sensitivity of the used protocols in RV characterization from country to country. Therefore, using a uniform protocol for RV surveillance in all countries would provide an accurate picture of the burden of RV diseases among countries. Three studies provided us with data on the duration stay of hospitalized children with a minimum duration of three days. This finding is similar to another review conducted on data collected during 1999-2009 from the Eastern Mediterranean Region(49). Globally, this duration was decreased to 2.5 days in a study from Sweden (52). The current review showed that the criteria of resource utilization used for patients infected with RV were similar in all countries. Also, the hospital admission and disease severity due to RV gastroenteritis were higher than those of non-RV gastroenteritis, which is similar to data reported in the region during 1999-2009 (49) and western Europe (53).

Finally, only one study from Tunisia conducted in 2015 contained data on health care utilization, where the medical cost of hospitalized children due to RV infection ranged from US\$245 to \$345 (33). This cost was lower than those costs reported during 1999-2009 in the studied region (ranging from US\$ 467 to \$1117) (49) and in western Europe (ranging from 2008 US\$ 1949 to \$2398 (54). Moreover, no data was available on the rotavirus fatalities in all our selected studies. From a previous review, annual deaths rates due to $\mathrm{RV}$ gastroenteritis ranged from 0 to 112 per 10000 children below 5 years of age in the Eastern Mediterranean Region during 19992009 (49).

\section{Conclusion}

Data on mortality and medical costs is limited to the studied countries. However, the available data showed that RV diarrhoea is a common disease in the Eastern Mediterranean Region, affecting the paediatric population health. Currently, two or three genotype combinations, including $\mathrm{G}_{1} \mathrm{P}[8], \mathrm{G} 9 \mathrm{P}[8]$ and $\mathrm{G}_{2} \mathrm{P}[4]$ are predominant in the region. Thus, the current Rotarix vaccine might be suitable to reduce the rates of morbidity and mortality caused by $\mathrm{RV}$ infection. However, new vaccines rather than Rotarix are desired to contain the other predominant genotypes of $\mathrm{RV}$ such as $\mathrm{G}_{9} \mathrm{P}[8]$ and $\mathrm{G}_{2} \mathrm{P}[4]$ in the region.

Funding: None.

Competing interests: None declared.

\section{La gastro-entérite à rotavirus chez les enfants hospitalisés de moins de 5 ans dans la Région de la Méditerranée orientale : analyse \\ Résumé}

Contexte : Le rotavirus est l'une des principales causes mondiales de diarrhée aiguë chez les enfants de moins de 5 ans.

Objectifs : La présente recherche documentaire vise à évaluer la diarrhée à rotavirus chez les enfants hospitalisés de moins de 5 ans dans la Région de la Méditerranée orientale entre 2010 et 2016. Les données de chaque pays ont été extraites et comparées.

Méthodes : Une recherche documentaire approfondie a été effectuée à l'aide des bases de données suivantes : PubMed, Google Scholar et Science Direct, en utilisant le mot-clé « rotavirus ». La recherche a été limitée aux articles publiés entre janvier 2010 et décembre 2016.

Résultats : La recherche a permis d'identifier 28 études. La gastro-entérite à rotavirus a été identifiée dans 19\%-78,2\% de tous les échantillons de diarrhée testés, principalement chez les enfants âgés d'un an ou moins. Le rotavirus était présent tout au long de l'année, avec une incidence maximale pendant l'automne et l'hiver. Le génotype circulant G1P[8] était la combinaison prédominante, suivie du G9P[8] et G2P[4]. Sur 28 études, une seule a examiné la charge économique qui variait de USD 245 à USD 345 par enfant hospitalisé suite à une diarrhée due au rotavirus. De plus, la durée minimale d'hospitalisation était de trois jours. Il n'y avait pas de données disponibles sur les taux de mortalité associée à la gastroentérite due au rotavirus dans les études sélectionnées. 
Conclusions : Cette recherche montre que le rotavirus est l'un des agents pathogènes les plus significatifs à l'origine d'une morbidité et d'une mortalité dans la population pédiatrique des pays de la Région de la Méditerranée orientale. Les données produites par cette recherche documentaire pourraient aider les agents de santé publique à réduire la mortalité et la morbidité associées à la gastro-entérite à rotavirus dans la Région.

$$
\text { شحمد نصر فتحي شاهئ المعدة والأمعاء الناشئ عن الإصة مر اجة بابة بالفيروسة العجلية بين الأطفال دون الخامسة داخل المستشفيات في إقليم }
$$

$$
\begin{aligned}
& \text { الخلفية: تُعَدُّ الفيروسة العجلية أحد الأسباب الأساسية التي تسبب الإسهال الحاد عند الأطفال دون الخامسة على مستوى العالم. }
\end{aligned}
$$

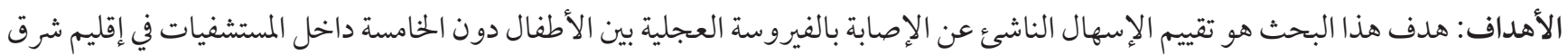

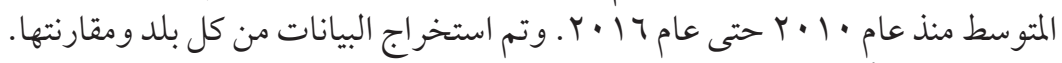

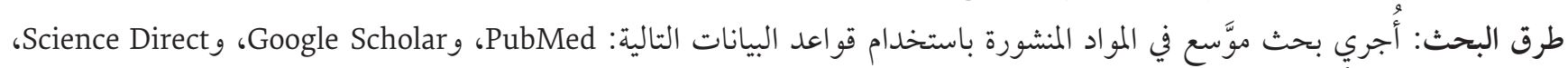

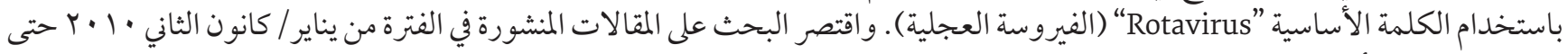

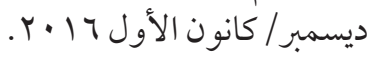

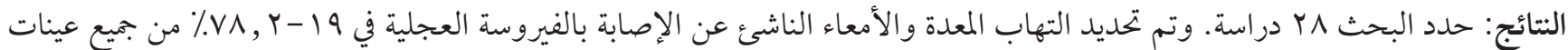

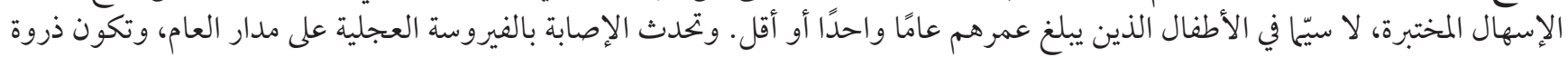

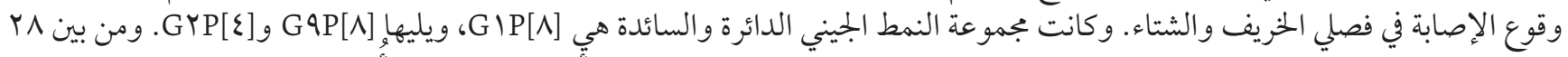

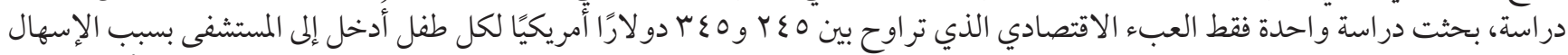

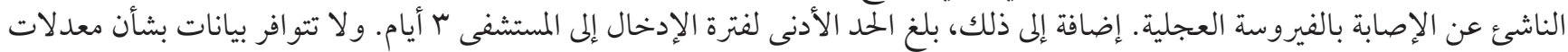

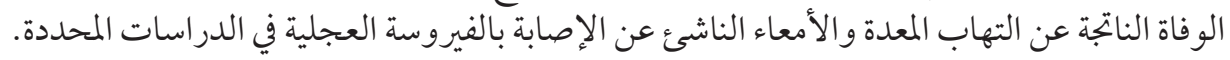

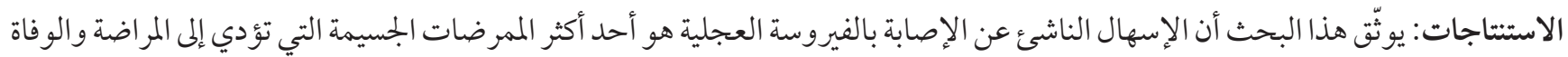

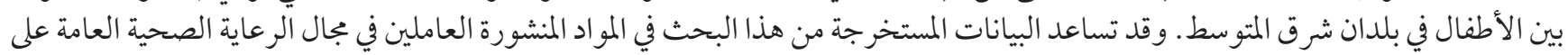

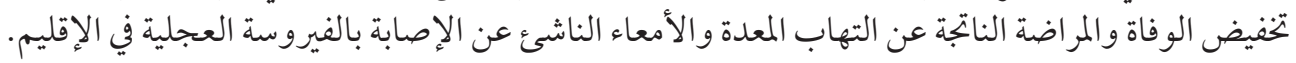

\section{References}

1. Parashar UD, Hummelman EG, Bresee JS, Miller MA, Glass RI. Global illness and deaths caused by rotavirus disease in children. Emerg Infect Dis. 2003;9(5):565-72. http://dx.doi.org/10.3201/eid0905.020562

2. Parashar UD, Burton A, Lanata C, Boschi-Pinto C, Shibuya K, Steele D, et al. Global mortality associated with rotavirus disease among children in 2004. J Infect Dis. 2009;200 s1:S9-15. http://dx.doi.org/10.1086/605025

3. Telmesani AM. Oral rehydration salts, zinc supplement and rota virus vaccine in the management of childhood acute diarrhea. J Family Community Med. 2010;17(2):79-82. http://dx.doi.org/10.4103/1319-1683.71988

4. Hoshino Y, Jones RW, Ross J, Honma S, Santos N, Gentsch JR, et al. Rotavirus serotype G9 strains belonging to VP7 gene phylogenetic sequence lineage 1 may be more suitable for serotype G9 vaccine candidates than those belonging to lineage 2 or 3 . J Virol. 2004;78(14):7795-802. http://dx.doi.org/10.1128/JVI.78.14.7795-7802.2004

5. Papp H, Matthijnssens J, Martella V, Ciarlet M, Bányai K. Global distribution of group A rotavirus strains in horses: a systematic review. Vaccine. 2013;31(48):5627-33. http://dx.doi.org/10.1016/j.vaccine.2013.08.045

6. Bányai K, Laszlo B, Duque J, Steele AD, Nelson EA, Gentsch JR, et al. Systematic review of regional and temporal trends in global rotavirus strain diversity in the pre rotavirus vaccine era: Insights for understanding the impact of rotavirus vaccination programs. Vaccine. 2012;30:A122-30. http://dx.doi.org/10.1016/j.vaccine.2011.09.111

7. Estes MK, Greenberg HB. Rotaviruses. In: Knipe DM, Howley PM (editors). Fields Virology. Philadelphia: Lippincott/Williams \& Wilkins; 2013. pp. 1347-401.

8. Greenberg HB, Estes MK. Rotaviruses: from pathogenesis to vaccination. Gastroenterology. 2009;136(6):1939-51. http://dx.doi. org/10.1053/j.gastro.2009.02.076

9. Ruuska T, Vesikari T. Rotavirus disease in Finnish children: use of numerical scores for clinical severity of diarrhoeal episodes. Scand J Infect Dis. 1990;22(3):259-67. http://dx.doi.org/10.3109/00365549009027046

10. Musawi MA, Zainaldeen H, Shafi F, Anis S, Deantonio R. Rotavirus gastroenteritis in children under 5 years in the Kingdom of Bahrain: hospital-based surveillance. Clin Epidemiol. 2013;5:269-75. 
11. Matson DO, Abdel-Messih IA, Schlett CD, Bok K, Wienkopff T, Wierzba TF, et al. Rotavirus genotypes among hospitalized children in Egypt, 2000-2002. J Infect Dis. 2010;202 S1:S263-5. http://dx.doi.org/10.1086/653581

12. El-Shabrawi M, Salem M, Abou-Zekri M, El-Naghi S, Hassanin F, El-Adly T, et al. The burden of different pathogens in acute diarrhoeal episodes among a cohort of Egyptian children less than five years old. Prz Gastroenterol. 2015;3:173-80. http://dx.doi. org/10.5114/pg.2015.51186

13. Kargar M, Najafi A, Zandi K, Hashemizadeh H. Genotypic distribution of rotavirus strains causing severe gastroenteritis in children under 5 years old in Borazjan, Iran. Afr J Microbiol Res. 2011;5(19):2936-41. http://dx.doi.org/10.5897/AJMR11.347

14. Modaress S, Rahbarimanesh AA, Edalat R, Sohrabi A, Modarres S, Gomari H, et al. Human Rotavirus Genotypes Detection among Hospitalized Children, A study in Tehran, Iran. Arch Iran Med. 2011;14:39-45.

15. Najafi A, Kargar M, Jafarpour T. Burden and Typing of Rotavirus Group A in Children with Acute Gastroenteritis in Shiraz, Southern Iran. Iran Red Crescent Med J. 2012;14:531-40.

16. Kargar M, Zare M, Najafi A. Molecular Epidemiology of Rotavirus Strains Circulating among Children with Gastroenteritis in Iran. Iran J Pediatr. 2012;22:63-9.

17. Kargar M, Akbarizadeh AR. Prevalence and Molecular Genotyping of Group A Rotaviruses in Iranian Children. Indian J Virol. 2012;23(1):24-8. http://dx.doi.org/10.1007/s13337-012-0070-7

18. Kajbaf ZT, Shamsizadeh A, Kavandi G, Macvandi M. Relative frequency of rotavirus and adenovirus among Children Aged 1-60 Months Hospitalized With Acute Diarrhoea in South-Western, Iran. Jundishapur J Microbiol. 2012;6(1):47-50. http://dx.doi. org/10.5812/jjm.4072

19. Kargar M, Khodadadi P, Najafi A, Ansari H. Predominant of rotavirus G8 genotype in hospitalized children with acute gastroenteritis in Yasuj, Iran. Eur Rev Med Pharmacol Sci. 2014;18:699-702.

20. Khoshdel A, Parvin N, Doosti A, Eshraghi A. Prevalence and molecular characterization of rotaviruses as causes of nosocomial diarrhea in children. Turk J Pediatr. 2014;56:469-74.

21. Mousavi Nasab SD, Sabahi F, Makvandi M, Mirab Samiee S, Nadji SA, Ravanshad M. Epidemiology of Rotavirus-Norovirus Co-Infection and Determination of Norovirus Genogrouping among Children with Acute Gastroenteritis in Tehran, Iran. Iran Biomed J. 2016;20:280-6.

22. Alani AO, Ai-Rawi AS, Salih KA, Al-Mawla GOS. Common Rota Virus Gastroenteritis in Children under 5 Years in Maternity and Children Teaching Hospital, western Iraq. Anb Med J. 2012;10:1-7.

23. Ahmed S, Klena J, Albana A, Alhamdani F, Oskoff J, Soliman M, et al. Characterization of human rotaviruses circulating in Iraq in 2008: atypical G8 and high prevalence of P[6] strains. Infect Genet Evol. 2013;16:212-7. http://dx.doi.org/10.1016/j.meegid.2012.12.003

24. Kaplan NM, Kirby A, Abd-Eldayem SA, Dove W, Nakagomi T, Nakagomi O, et al. Detection and molecular characterization of rotavirus and norovirus infections in Jordanian children with acutegastroenteritis. Arch Virol. 2011;156(8):1477-80. http://dx.doi. org/10.1007/s00705-011-0996-x

25. Salem K, Bdour S, Zeller M, Van Ranst M, Matthijnssens J. Genotypes of rotavirus strains circulating in Amman, Jordan, in 2006/07 and their significance for the potential effectiveness of future rotavirus vaccination. Arch Virol. 2011;156:1543-50.

26. Abugalia M, Cuevas L, Kirby A, Dove W, Nakagomi O, Nakagomi T, et al. Clinical features of molecular epidemiology of rotavirus and norovirus infections Libyan children. J Med Virol. 2011;83(10):1849-56. http://dx.doi.org/10.1002/jmv.22141

27. Benhafid M, Rguig A, Trivedi T, Elqazoui M, Teleb N, Mouane N, et al. Monitoring of rotavirus vaccination in Morocco: establishing the baseline burden of rotavirus disease. Vaccine. 2012;30(46):6515-20. http://dx.doi.org/10.1016/j.vaccine.2012.08.058

28. Benhafid M, Elomari N, Elqazoui M, Meryem AI, Rguig A, Filali-Maltouf A, et al. Diversity of rotavirus strains circulating in children under 5 years of age admitted to hospital for acute gastroenteritis in Morocco, June 2006 to May 2009. J Med Virol. 2013;85:354-62.

29. El Qazoui M, Oumzil H, Baassi L, El Omari N, Sadki K, Amzazi S, et al. Rotavirus and norovirus infections among acute gastroenteritis children in Morocco. BMC Infect Dis. 2014;14(1):300. http://dx.doi.org/10.1186/1471-2334-14-300

30. Obied OE. Characterization of human rotavirus subgroups and serotypes in children under five with acute gastroenteritis in a Saudi Hospital. J Family Community Med. 2011;18:22-25.

31. Tayeb HT, Balkhy HH, Aljuhani SM, Elbanyan E, Alalola S, Alshaalan M. Increased prevalence of rotavirus among children associated gastroenteritis in Riyadh Saudi Arabia. Virol J Dec. 2011;8:548.

32. Khalil M, Azhar E, Kao M, Al-Kaiedi N, Alhani H, Al Olayan I, et al. Gastroenteritis attributable to rotavirus in hospitalized Saudi Arabian children in the period 2007-2008. Clin Epidemiol. 2015;7:129-37.

33. Aly M, Al Khairy A, Al Johani S, Balkhy H. Unusual rotavirus genotypes among children with acute diarrhea in Saudi Arabia. BMC Infect Dis. 2015;15:192.

34. Soltani MS, Salah AB, Bouanene I, Trabelsi A, Sfar MT, Harbi A, et al. Epidemiology and medical cost of hospitalization due to rotavirus gastroenteritis among children under 5 years of age in the central-east of Tunisia. East Mediterr Health J. 2015;21:584-90.

35. Durmaz R, Kalaycioglu AT, Acar S, Bakkaloglu Z, Karagoz A, Korukluoglu G, et al. Turkish Rotavirus Surveillance Network: Prevalence of rotavirus genotypes in children younger than 5 years of age before the introduction of a universal rotavirus vaccination program: report of rotavirus surveillance in Turkey. PLoS One. 2014;9:e113674. 
36. Bozdayi G, Altay A, Yahiro T, Ahmed S, Meral M, Dogan B, et al. Re-emergence of genotype G9 during a five-and-a-half-year period in Turkish children with rotavirus diarrhea. Arch Virol. 2016;161:2879-84.

37. Howidi M, Balhaj G, Yaseen H, Gopala K, Van Doorn LJ, DeAntonio R. Burden and genotyping of rotavirus disease in the United Arab Emirates. Hum Vaccin Immunotheraputic. 2014;10:2284-89.

38. Al-Badani A, Al-Areqi L, Majily A, Al-Sallami S, Al-Madhagi A, Amood Al-Kamarany M. Rotavirus Diarrhea among Children in Taiz, Yemen: Prevalence-Risk Factors and Detection of Genotypes. Int J Pediatr. 2014; 2014:928529.

39. CDC: Rotavirus Surveillance --- Worldwide, 2001-2008. November 21, 2008 / 57(46); 1255-1257. http://www.cdc.gov/mmwr/preview/mmwrhtml/mm5746a3.htm

40. Forster J, Guarino A, Parez N, Moraga F, Román E, Mory O, et al. Hospital-based surveillance to estimate the burden of rotavirus gastroenteritis among European children younger than 5 years of age. Pediatrics. 2009;123:e393-400.

41. Van Damme P, Giaquinto C, Huet F, Gothefors L, Maxwell M, Van der Wielen M. REVEAL Study Group. Multicenter prospective study of the burden of rotavirus acute gastroenteritis in Europe, 2004-2005: the REVEAL study. J Infect Dis. 2007;1:S4-16.

42. Kamiya H, Nakano T, Inoue M, Kamiya H, Abd TT, Patel M, et al. A retrospective evaluation of hospitalizations for acute gastroenteritis at 2 sentinel hospitals in central Japan to estimate the health burden of rotavirus. J Infect Dis. 2009;1:S140-6.

43. Khalil M, Azhar E, Kao M, Al-Kaiedi N, Alhani H, Al Olayan I, et al. Gastroenteritis attributable to rotavirus in hospitalized Saudi Arabian children in the period 2007-2008. Clin Epidemiol. 2015;7:129-37.

44. Jiang B, Gentsch JR, Glass RI. The role of serum antibodies in the protection against rotavirus disease: an overview. Clin Infect Dis. 2002 15;34(10):1351-61.

45. McNulty MS. Rotaviruses. J Gen Virol 1978;40:1-18.

46. Moe K, Shirley JA. The effects of relative humidity and temperature on the survival of human rotavirus in faeces. Arch Virol. 1982;72:179-86.

47. Ansari SA, Springthorpe VS, Sattar SA. Survival and vehicular spread of human rotaviruses: possible relation to seasonality of outbreaks. Rev Infect Dis. 1991;13:448-61.

48. Dhital S, Sherchand JB, Pokhrel BM, Parajuli K, Shah N, Mishra SK, Sharma S, Kattel HP, Khadka S, Khatiwada S, Parajuli N, Rijal B. Molecular epidemiology of Rotavirus causing diarrhea among children less than five years of age visiting national level children hospitals, Nepal. BMC Pediatr. 2017; 7:17(1):101.

49. Melhem NM, Zaraket H, Kreidieh K, Ali Z, Hammadi M, Ghanem S, Hajar F, Haidar A, Inati A, Rajab M, Fakhouri H, Ghanem B, Baasiri G, Dbaibo G.Clinical and epidemiological characteristics of norovirus gastroenteritis among hospitalized children in Lebanon. World J Gastroenterol. 2016; 28:22(48):10557-10565.

50. Khoury H, Ogilvie I, El Khoury AC, Duan Y, Goetghebeur MM. Burden of rotavirus gastroenteritis in the Middle Eastern and North African pediatric population. BMC Infect Dis. 2011;11:9.

51. Ogilvie I, Khoury H, El Khoury AC, Goetghebeur MM. Burden of rotavirus gastroenteritis in the pediatric population in Central and Eastern Europe: serotype distribution and burden of illness. Hum Vaccin. 2011;7:523-33.

52. Iturriza-Gomara M, Green J, Brown DW, Ramsay M, Desselberger U, Gray JJ. Molecular epidemiology of human group A rotavirus infections in the United Kingdom between 1995 and 1998. J Clin Microbiol. 2000; 38: 4394-4401.

53. Ogilvie I, Khoury H, Goetghebeur MM, El Khoury AC, Giaquinto C. Burden of community-acquired and nosocomial rotavirus gastroenteritis in the pediatric population of Western Europe: a scoping review. BMC Infect Dis. 2012; 12:62.

54. Giaquinto C, Van Damme P, Huet F, Gothefors L, Maxwell M, Todd P, et al. Clinical consequences of rotavirus acute gastroenteritis in Europe, 2004-2005: the REVEAL study. J Infect Dis. 2007; 195: S26-35. 